\title{
Recommended practices for the management of surgical smoke and bio-aerosols for perioperative nurses in Thailand
}

Follow this and additional works at: https://www.journal.acorn.org.au/jpn

Part of the Health Services Administration Commons, Health Services Research Commons, Perioperative, Operating Room and Surgical Nursing Commons, and the Surgery Commons

\section{(c) (i)}

This work is licensed under a Creative Commons Attribution 4.0 License.

\section{Recommended Citation}

Asdornwised, Usavadee; Pipatkulchai, Daranee; Damnin, Suwat; Chinswangwatanakul, Vitoon; Boonsripitayanon, Mongkol; and Tonklai, Sununtha (2018) "Recommended practices for the management of surgical smoke and bio-aerosols for perioperative nurses in Thailand," Journal of Perioperative Nursing: Vol. 31 : Iss. 1 , Article 3.

Available at: https://doi.org/10.26550/2209-1092.1022

https://www.journal.acorn.org.au/jpn/vol31/iss1/3

This Article is brought to you for free and open access by Journal of Perioperative Nursing. It has been accepted for inclusion in Journal of Perioperative Nursing by an authorized editor of Journal of Perioperative Nursing. 


\section{Authors}

Assoc. Prof. Usavadee Asdornwised PhD (Nursing), MS

Faculty of Nursing, Mahidol University

Mrs. Daranee Pipatkulchai

MSN

Head of Perioperative Nursing Division Nursing Department, Siriraj Hospital, Faculty of Medicine, Mahidol University

Mr. Suwat Damnin

MS

Head of Occupational Health Division, Siriraj Hospital, Mahidol University

Dr. Vitoon Chinswangwatanakul $M D$

Surgical Department, Division of General Surgery, Faculty of Medicine, Mahidol University

Dr. Mongkol Boonsripitayanon MD

Surgical Department, Division of Head, Neck and Breast Surgery, Faculty of Medicine, Mahidol University

Ms. Sununtha Tonklai

MSN

Surgical Nursing Division, Nursing Department, Siriraj Hospital, Mahidol University

\section{Corresponding author}

Assoc. Prof. Usavadee Asdornwised Faculty of Nursing, Mahidol University 2 Wanglang Rd, Bangkoknoi, Bangkok

10700, Thailand

E: usavadee.asd@mahidol.ac.th

\title{
Recommended practices for the management of surgical smoke and bio-aerosols for perioperative nurses in Thailand
}

\begin{abstract}
Evidence-based guidelines for the management of surgical smoke and bioaerosols for perioperative nurses are necessary to improve the quality of care for patients and to ensure a safe environment in operating rooms. A survey of 377 operating room (OR) nurses throughout Thailand was used to assess the incidence of health problems related to surgical smoke exposure, as well as the current practices for these substances. A high percentage of OR nurses reported little or no use of smoke evacuation tools such as central smoke evacuation systems (100 per cent), portable smoke evacuation units (82 per cent), wall suction with inline filters (56.5 per cent) or laparoscopic evacuation/ filtration systems (63.7 per cent) during surgery. Most of the perioperative nurses suffered from headaches and/or sore throats. Due to the wide range of deleterious health issues that arise from exposure to surgical smoke, it is critical that perioperative nurses closely adhere to best practice guidelines for minimising this environmental hazard.
\end{abstract}

Keywords: recommended practices, management, surgical smoke, perioperative nurses

\section{Introduction}

The National Institute of Occupational Safety and Health (NIOSH) and the Centers for Disease Control and Prevention (CDC) have studied electrosurgical smoke at length. Smoke and bio-aerosols are routinely produced by surgical instruments including lasers, electrosurgical units, radiofrequency devices, ultrasonic devices and power tools. Plume and bio-aerosols contain odour-causing and odourless toxic gases and vapors such as benzene, hydrogen cyanide and formaldehyde, as well as dead and live cellular debris (including blood fragments), bacteria and viruses ${ }^{1-9}$. The risk of inhaling surgical smoke and bio-aerosols has been linked to headaches, respiratory problems, eye and skin irritation, infection $n^{1,2}$ and mutagenic and carcinogenic potential in patients, perioperative nurses, anesthesiologists and other operating room personnel ${ }^{1,4,10-12}$.

The hazards of surgical smoke and bio-aerosols have been an environmental exposure concern for many years. The risks from inhalation and the resultant health disorders, however, have not led to mandatory regulations to prevent exposure in the clinical workplace or operating room. Perioperative nurses and other OR personnel have long suffered from inhalation of surgical smoke or plume. Unprotected workers remain at risk of irritation to the upper respiratory tract and eyes, as well as additional reactions from these chemical agents. Previous studies indicated that common complaints associated with exposure to surgical smoke include headaches, watering eyes, cough, burning throat, nausea, drowsiness, dizziness, sneezing and rhinitis ${ }^{13}$. In addition, previous studies have implicated surgical smoke in 
viral disease transmission human related to human papilloma virus (HPV), human immunodeficiency virus (HIV) and hepatitis, and various carcinogens were reported from this exposure ${ }^{1,11}$. The Association of perioperative Registered Nurses (AORN) serves as the practicing authority for reporting the hazards of surgical smoke and bio-aerosols and provides practice recommendations to control this workplace health threat. Currently, there are multiple AORN practice guidelines and position statements including:

- AORN Position statement on surgical smoke and bio-aerosols ${ }^{14}$

- Recommended practices for electrosurgery ${ }^{15}$

- Recommended practices for a safe environment of care ${ }^{16}$

- Recommended practices for laser safety in perioperative practice settings ${ }^{17}$

- Recommended practices for minimally invasive surgery ${ }^{18}$

- Clinical resources - Management of surgical smoke ${ }^{19}$.

More than 100000 health professionals, including 7000 perioperative nurses in Thailand, are exposed to surgical smoke every year. The use of recommended practices to control this smoke among perioperative nurses and health personnel in Thailand has not been assessed. In addition, there is little information available about the health problems associated with surgical smoke and bioaerosol inhalation among exposed Thai health care personnel and patients. Our experience working as perioperative nurses or teachers in the operating room found that many nurses have complained about such symptoms as coughing, sneezing, sore throat, and respiratory tract and eye irritation. These symptoms appear to be related to exposure from OR smoke.

Although perioperative nurses use a surgical mask during surgery, even when worn correctly these masks can only filter particles which are larger than $5.0 \mu \mathrm{m}^{20}$. Therefore, smoke particles less than $5.0 \mu \mathrm{m}$ in size can pass through regular masks into the respiratory tract and deposit in the bronchioles and alveoli. Toxic gases such as carboxyhaemoglobin or methaemoglobin can also be inhaled. The proper use of equipment for smoke evacuation along with personal protective equipment (PPE) in Thailand could significantly improve the quality of the practice and safety in health care facilities.

\section{Study purpose}

The main objective of this study was to survey perioperative nurses in each region of Thailand in order to assess the use of recommended practices to prevent exposure to surgical smoke and bio-aerosols. This included the use of evacuation systems and units for preventing surgical smoke and bio-aerosols, the use of personal protective equipment, and the study of the incidence of health problems among OR nurses related to surgical smoke and bioaerosols. The study and survey were based on evidence-based practice discussed in research studies and AORN position statements on the containments in surgical smoke and bio-aerosols.

\section{Research questions}

The specific research questions were:

1. What percentage of perioperative nurses adhere to AORN's recommended practice guidelines for controlling surgical smoke and bio-aerosols in operating rooms?

2. What percentage of perioperative nurses' experience health problems related to smoke and bio-aerosols exposure?

\section{Literature review}

\section{Surgical smoke hazards}

A review of the research indicated that surgical smoke and bio-aerosols are harmful to surgical patients as well as the surgical team (surgeons, nurses and anesthesiologists). This harm results from exposure to surgical plume or carbon dioxide levels that exceed recommendations for general surgery or laparoscopic surgery with electrocautery. Surgical smoke or plume includes chemicals such as benzene, ethylbenzene, toluene and methyl propane ${ }^{19}$ and, of greatest concern, carbon monoxide (CO) and acrylonitrile. In addition, and also of significant concern, this smoke may contain hydrogen cyanide, formaldehyde, benzene and virus particles'. Many research studies 1,13,21 have expressed concern related to the impact of surgical smoke on the perioperative care team's health, especially in relation to respiratory problems.

\section{Guidelines for surgical smoke prevention}

The amount of harmful particles from surgical smoke and types of surgery were considered in the present study in order to recommend appropriate equipment or evacuation methods ${ }^{1,20}$. These guidelines regarding harmful exposure to surgical smoke can be readily found in the AORN Position Statement and from the $\mathrm{NIOSH}$, the Australian College of Perioperative Nurses (ACORN) 22 and the International Federation of Perioperative Nurses (IFPN). Previous studies ${ }^{21-23}$ have indicated that many surgical team members, especially perioperative nurses, have related discomfort in using such methods or have denied the necessity of their use. Although many organisations such as AORN, NIOSH, ACORN and 
the CDC strongly recommend the evacuation of surgical smoke using specific evacuation methods, regulations for this process are not mandated in perioperative areas in Thailand. Most hospitals in Thailand have no explicit policy for controlling surgical smoke and sometimes there is no smoke evacuation system in the operating room. In addition, training programs to protect perioperative nurses from smoke and bio-aerosols are not provided regularly.

\section{Health problems associated with surgical smoke}

A number of studies, 1,5,0,12,13 have revealed specific surgical hazards associated with the perioperative health care team's exposure to surgical smoke, and some of the symptoms associated with this exposure are listed below ${ }^{5,10,13,21}$.

- eye irritation

- headache

- nausea

- acute or chronic inflammatory respiratory changes

- asthma

- chronic bronchitis

- light-headedness

- nasopharyngeal lesions

- throat irritation

- weakness and fatigue.

The surgical care team should recognise the hazards of surgical smoke and should play an active role in protecting themselves and their patients from these hazards.

\section{Methods}

The study is of a cross-sectional survey design focusing on perioperative nurses in Thailand in order to evaluate the use of recommended practices for controlling surgical smoke and bioaerosols in operating rooms.

\section{Sample}

Recruitment criteria consisted of the following: perioperative nurses who had two or more years of experience working in the OR, were trained as perioperative nurse specialists or had attended an OR nurse management conference. These groups were identified as having the required knowledge of and training in the recommended practices for smoke and bio-aerosols prevention and the equipment used for protection.

\section{Sample size}

A sample of 366 OR nurses was needed in order to confirm a 95 per cent confidence level for this population size (7500 OR nurses) using a margin of error of 5 per cent and a response distribution of 50 per cent; however, 450 questionnaires were distributed to ensure an adequate return rate. A sample size calculator (www.raosoft.com/ samplesize.html) was used to make these decisions.

\section{Instruments}

In this study, all respondents were asked to complete the 'Recommended practice tool for surgical smoke and bio-aerosols prevention'. The perioperative nurses also completed a survey in order to ascertain any health problems related to surgical smoke and bioaerosols that they had.

\section{Recommended practice tool for surgical smoke and bio-aerosols prevention among perioperative nurses}

For the purpose of this study, a tool was developed by the investigator based on a comprehensive review of the literature, the AORN 'Position statement on surgical smoke and bio-aerosols' ${ }^{\prime / 4}$ and 'Recommended practices for electrosurgery ${ }^{\prime 5}$. This tool used a five-point Likert scale ( 1 = never and 5 = always) for perioperative nurses to indicate how often they used or followed each recommended practice item. If a response indicated that a practice was not followed, an explanation was requested concerning why this deviation from the guideline occurred. After the questionnaire was developed, three experts, including an occupational health and safety professional, a surgeon, and a perioperative specialist nurse, validated the content. The experts recommended a revision of some of the wording. A coefficient of agreement among the three experts was calculated and the result was 1 . Then a pilot study of 30 participants from an OR management conference was conducted in order to assess its reliability. Cronbach's alpha level was 0.75 (respectable reliability). The alpha coefficient for all of the participants was 0.80 .

\section{Health problems related to smoke and bio-aerosols tool}

This tool was developed by the investigator based on a comprehensive review of the literature which was conducted in order to identify the known health problems associated with exposure to surgical smoke and bio-aerosols. The most prevalent problems identified were eye irritation, headaches, nausea/ dizziness, coughing/sneezing, asthma, chronic bronchitis, sore throat and weakness ${ }^{10}$. The participants were asked to indicate if these health problems were present and the severity of any symptoms associated with the health problems. The respondents scored the severity of their health problems on a scale from one to seven and scored their health problems related to smoke and bio-aerosols on a scale from one to seven regarding eight health risk problems. Possible range of total scores is eight to 56 where 56 
indicated the highest risk. Higher scores indicated higher presence and severity of symptoms.

After the questionnaire was developed, three experts, including a chest medicine doctor, a thoracic surgeon and a perioperative specialist nurse, validated the content. The content validity index (CVI) for this instrument was 1. A pilot study of 30 participants from an OR management conference was then conducted in order to assess its reliability. Cronbach's alpha level was 0.8 .

\section{Data collection procedures}

The study was conducted after approval from the Institutional Review Board of the Faculty of Nursing, Mahidol University. The respondents were given a participant information sheet that informed them of their right to withdraw from the study at any time, and they were assured that their identities and information would be kept confidential. After recruitment, each subject signed a consent form, completed a demographic form, and provided information regarding any allergies they had and their relevant medical history. The two questionnaires were sent to the participants, who worked in secondary or tertiary hospitals in Thailand, and they were asked to complete the questionnaires and return them to the researchers by mail or email. The average time needed to complete the survey was approximately 30 minutes.

\section{Data analysis}

Demographic data such as age, education, amount of OR experience and knowledge of the hazard of surgical smoke and bio-aerosols before the survey was presented in terms of frequency, mean and standard deviation. A recommended practice data survey and information

Table 1: Characteristics of respondents $(\mathrm{N}=377)$

\begin{tabular}{|c|c|c|c|c|c|}
\hline \multicolumn{3}{|l|}{ Characteristics } & $\mathrm{n}$ & Per cent & Mean \\
\hline \multicolumn{3}{|l|}{ Age } & & & $\begin{array}{l}43 \text { years } \\
\text { (range } 23-61 \\
\text { years) }\end{array}$ \\
\hline \multirow{3}{*}{\multicolumn{2}{|c|}{ Education }} & BS & 332 & 88.1 & \\
\hline & & MS & 40 & 10.6 & \\
\hline & & PhD & 5 & 1.3 & \\
\hline \multicolumn{3}{|c|}{ Amount of OR experience } & & & $\begin{array}{l}19 \text { years } \\
\text { (range } 2-36 \\
\text { years) }\end{array}$ \\
\hline \multirow{2}{*}{\multicolumn{2}{|c|}{$\begin{array}{l}\text { Knowledge about hazard } \\
\text { of surgical smoke and bio- } \\
\text { aerosols before survey }\end{array}$}} & no & 30 & 8 & \\
\hline & & yes & 347 & 92 & \\
\hline \multirow{4}{*}{$\begin{array}{l}\text { Source of } \\
\text { knowledge about } \\
\text { surgical smoke }\end{array}$} & \multicolumn{2}{|l|}{ Media } & 100 & 28.8 & \\
\hline & \multicolumn{2}{|c|}{$\begin{array}{l}\text { Department } \\
\text { head / operating } \\
\text { room nurses }\end{array}$} & 49 & 14.1 & \\
\hline & \multicolumn{2}{|c|}{ Colleagues } & 118 & 34.0 & \\
\hline & \multicolumn{2}{|c|}{ Other sources } & 80 & 23.1 & \\
\hline
\end{tabular}

about health problems related to smoke and bio-aerosols exposure were also presented in terms of frequency, mean and standard deviation. Data was managed and analysed using the Statistical Package for the Social Science Version 17 (SPSS) software program on a personal computer.

\section{Results}

\section{Demographic data}

Of the 450 questionnaires distributed, 377 were completed for a response rate of 84 per cent. The respondents recruited for this study consisted of OR nurses from the following regions in Thailand: the northern (19 per cent), central (26 per cent), southern ( 9 per cent), northeastern (16 per cent) and eastern (5 per cent) regions, while OR nurses from private hospitals represented 11 per cent. The data indicated that the participants worked at secondary or tertiary hospitals in every major region of Thailand. Table 1 summarises the demographic data and the nurses' knowledge about the hazards of surgical smoke and bio-aerosols before the survey. The mean age of the perioperative nurses responding to this study was 43 years (range 23 to 61 years). Of the respondents, 88.1 per cent had a bachelor's degree and 10.6 per cent had a master's degree. The average work experience in the OR was 19 years (range 2 to 36 years). They usually worked at least 8 hours per day and needed to be in the surgical field at least 7 hours per day. Most respondents (92 per cent) were aware of the hazards of surgical smoke from sources such as the media (28.8 per cent), department heads/ operating room nurses (14.1 per cent), colleagues (34 per cent), or other sources (23.1 per cent). 
Table 2: Level of adherence to recommended practice for controlling surgical smoke and bio-aerosols among perioperative nurses $(\mathrm{N}=377)$

\begin{tabular}{|c|c|c|c|c|c|c|}
\hline \multicolumn{2}{|c|}{$\begin{array}{l}\text { Recommended practice for controlling surgical smoke } \\
\text { and bio-aerosols in operating rooms }\end{array}$} & \multirow{2}{*}{$\begin{array}{l}\text { Always } \\
n(\%) \\
\quad 0\end{array}$} & \multirow{2}{*}{$\begin{array}{l}\text { Often } \\
\mathrm{n}(\%) \\
\\
\end{array}$} & \multirow{2}{*}{$\begin{array}{l}\text { Sometimes } \\
\mathrm{n}(\%) \\
\\
0\end{array}$} & \multirow{2}{*}{$\begin{array}{l}\text { Rarely } \\
\mathrm{n}(\%) \\
\\
\quad 0\end{array}$} & \multirow{2}{*}{$\begin{array}{l}\text { Never } \\
\text { n(\%) } \\
377(100)\end{array}$} \\
\hline $\begin{array}{l}\text { 1. Use equipment, with } \\
0.1 \mu \mathrm{m} \text { filtration at }\end{array}$ & $\begin{array}{l}\text { Central smoke evacuation } \\
\text { systems }\end{array}$ & & & & & \\
\hline $\begin{array}{l}\text { 99.999\% efficiency, } \\
\text { such as: }\end{array}$ & $\begin{array}{l}\text { Portable smoke } \\
\text { evacuation units }\end{array}$ & $34(9.0)$ & 0 & $34(9.0)$ & $69(18.3)$ & $240(63.7)$ \\
\hline & $\begin{array}{l}\text { Wall suction with inline } \\
\text { filter }\end{array}$ & $49(13.0)$ & $33(8.7)$ & $82(21.8)$ & $49(13.0)$ & $164(43.5)$ \\
\hline & $\begin{array}{l}\text { Laparoscopic evacuation/ } \\
\text { filtration systems }\end{array}$ & $103(27.3)$ & $34(9.0)$ & 0 & $34(9.0)$ & $206(54.7)$ \\
\hline & $\begin{array}{l}\text { Wall suction without } \\
\text { inline filter for evacuation } \\
\text { during surgery (not } \\
\text { recommended practice) }\end{array}$ & $148(39.3)$ & $115(30.5)$ & $49(13.0)$ & $49(13.0)$ & $16(4.2)$ \\
\hline \multirow[t]{2}{*}{$\begin{array}{l}\text { 2. Use personal protective } \\
\text { equipment }\end{array}$} & $\begin{array}{l}\text { High filtration surgical } \\
\text { masks worn properly }\end{array}$ & $95(25.2)$ & $63(16.7)$ & $29(7.7)$ & $95(25.2)$ & $95(25.2)$ \\
\hline & Protective eye wear & $110(29.2)$ & $95(25.2)$ & $110(29.2)$ & $47(12.4)$ & $15(4.0)$ \\
\hline $\begin{array}{l}\text { 3. Receive training in } \\
\text { protecting from surgical } \\
\text { smoke and bio-aerosols }\end{array}$ & & $17(4.6)$ & $105(27.8)$ & $75(19.9)$ & $105(27.8)$ & $75(19.9)$ \\
\hline $\begin{array}{l}\text { 4. The equipment to } \\
\text { protect from smoke } \\
\text { and bioaerosols was } \\
\text { demonstrated to the } \\
\text { health professional }\end{array}$ & & 0 & $90(23.9)$ & $76(20.1)$ & $121(32.1)$ & $90(23.9)$ \\
\hline $\begin{array}{l}\text { 5. Comply with the } \\
\text { guideline for protecting } \\
\text { from smoke and bio- } \\
\text { aerosols }\end{array}$ & & $45(11.9)$ & $106(28.1)$ & $106(28.1)$ & $30(8.0)$ & $90(23.9)$ \\
\hline $\begin{array}{l}\text { 6. Documentation and } \\
\text { regular training related } \\
\text { to smoke and bio- } \\
\text { aerosols }\end{array}$ & & 0 & 0 & $90(23.9)$ & $121(32.1)$ & $166(44.0)$ \\
\hline
\end{tabular}

Recommended practice for controlling surgical smoke and bio-aerosols among the perioperative nurses.

\section{Equipment usage to control surgical smoke and bio-aerosols}

The results in Table 2 indicate the level of adherence to recommended practices to control surgical smoke and bio-aerosols among perioperative nurses. The data showed that the most commonly used equipment to control surgical smoke in the OR was wall suction without an inline filter and that this was generally used only during surgery. The survey responses indicated that this system was used 'always' or 'often' by 69.8 per cent (263) of respondents. This system however is not considered sufficient for smoke evacuation according to established guidelines. Thirty-six percent of the perioperative nurses used laparoscopic evacuation/ filtration systems 'always' or 'often,' while 21.7 per cent (82) reported using wall suction with an inline filter, and nine per cent (34) reported the use of portable smoke evacuation units. None of the nurses reported that his or her OR used central 
Table 3: The perioperative nurses' health problems associated with surgical smoke $(\mathrm{N}=377)$

\begin{tabular}{|l|c|c|} 
& $\begin{array}{l}\text { Perioperative nurses } \\
\text { who had health } \\
\text { problem* } \\
n(\%)\end{array}$ & $\begin{array}{l}\text { Severity score** } \\
\text { Mean (Standard } \\
\text { Deviation) }\end{array}$ \\
Health problem & $298(79)$ & $2.9(1.6)$ \\
\hline headache & $279(74)$ & $2.6(1.5)$ \\
\hline sore throat & $278(73)$ & $3.1(1.8)$ \\
\hline coughing/sneezing & $274(72)$ & $2.5(1.5)$ \\
\hline weakness & $264(70)$ & $2.6(1.5)$ \\
\hline eye irritation & $238(63)$ & $2.4(1.5)$ \\
\hline nausea/dizziness & $196(51)$ & $2.2(1.5)$ \\
\hline chronic bronchitis & $79(20)$ & $1.8(1.4)$ \\
\hline asthma & & \\
\hline
\end{tabular}

* The respondents could answer more than one health problem associated with surgical smoke.

** Severity scores range from 1 to 7 .

smoke evacuation systems. Portable smoke evacuation units were used 'sometimes,' 'rarely,' or 'never' by nine per cent (34), 18.3 per cent (69) and 63.7 per cent (240) of respondents respectively, while laparoscopic evacuation/filtration systems were used 'rarely' or 'never' by nine per cent (34) and 54.7 per cent (206) of respondents respectively.

\section{Use of personal protective equipment}

Table 2 shows that most of the perioperative nurses adhered to guidelines involving the use of personal protective equipment. They reported using protective eyewear 'always' or 'often' (54.4 per cent, 205). Only 41.9 per cent (158) of the perioperative nurses indicated that they 'always' or 'often' used high filtration surgical masks.

\section{Receive training in protecting from surgical smoke and bio-aerosols}

As shown in Table 2, 67.6 per cent (255) of the perioperative nurses had received training in protection from smoke and bio-aerosols 'sometimes,' 'rarely,' or 'never,' while 76.1 per cent (287) of the nurses noted that demonstrations of equipment to control exposure to surgical smoke and bio-aerosols occurred 'sometimes' 'rarely' or 'never.' All of the perioperative nurses (100 per cent, 377) indicated that they 'sometimes,' 'rarely,' or 'never' received regular documentation or regular training related to smoke and bio-aerosols. In addition, 60 per cent (226) indicated that they 'sometimes,' 'rarely,' or 'never' used perioperative standards and recommended practices for controlling surgical smoke in the operating room. Only 40 per cent (151) of the perioperative nurses indicated that they 'always' or 'often' complied with the perioperative standards and recommended practice.

\section{Health problems associated with surgical smoke}

The presence of symptoms was high, as displayed in Table 3. The participants identified health problems associated with surgical smoke and bio-aerosols exposure, including headaches, sore throat, coughing/sneezing, weakness, eye irritation, nausea/dizziness, chronic bronchitis and asthma. Headache and sore throat were the most commonly reported, but coughing/ sneezing had the highest level of symptom severity. Overall, the levels of symptom severity were low.

\section{Discussion}

This study examined Thai perioperative nurses' adherence to recommended practices for controlling surgical smoke and bioaerosols, as well as the prevalence and severity of associated health problems. Adherence levels were low, which is consistent with the finding of many research studies.

\section{Recommended practice for controlling surgical smoke}

AORN and NIOSH have recommended that surgical smoke be evacuated by smoke evacuators in order to protect health personnel and patients from surgical smoke hazards. Since 1996 many societies such as NIOSH, AORN, IFPN, the Occupational Safety and Health Administration (OSHA), and the Canadian Standards Association (CSA) have raised awareness of the hazards of surgical smoke 1,3,14,25. However, nurses, surgeons, and other health professionals working in operating rooms in Thailand still experience surgical smoke-related problems. Change is complicated as professional organisations do not have the authority to regulate the control of surgical smoke. Additionally, nurses may have 
become accustomed to the smell of cautery or the scalpel dissection of human tissue during surgery. Further, most organisations in which perioperative nurses work do not follow the recommendations for controlling surgical smoke and smoke evacuation. ${ }^{21}$

The results also indicated that recommended OR equipment, such as portable smoke evacuation systems, laparoscopic evacuation/ filtration systems and wall suction with inline filters for controlling smoke, were used less than the guidelines recommend. This finding supports a study by Ball ${ }^{21}$ where it was indicated the respondents did not use smoke evacuators for most surgical procedures such as total hip replacement (69 per cent), mastectomy (49 per cent), tonsillectomy (69 per cent), laparoscopic dissection (62 per cent), microlaryngoscopy (50 per cent) and colonoscopy (44 per cent). However, the participating perioperative nurses in Ball's study usually used a smoke evacuator (54 per cent) during condyloma vaporisation.

Overall, the results supported the idea that in general there is a low level of equipment use in Thai operating rooms, with the exception of wall suction without a filter. The wall suction evacuates a small amount of smoke, less than 5 cubic feet per minute (cfm). While this is the most common method of controlling surgical smoke in the OR, it is not an effective method if the surgical procedure generates a large amount of smoke ${ }^{21}$.

Only 21.7 per cent of the perioperative nurses reported that they 'always' or 'often' used wall suction with an inline filter. Ten percent of the perioperative nurses provided more information noting they were not sure about the policy of changing inline filters according to the manufacturer's written instructions. In addition, the reasons stated why they did not use portable smoke evacuation units were cost, no requirement by surgeons, and the unavailability of equipment for smoke evacuation. The same results were reported in other studies in the USA U $^{21,24}$ and in New Zealand ${ }^{6}$. The patient's safety comes first, but health care workers also need protection from workplace hazards. Thus a safe working environment and appropriate equipment should be provided adequately in Thailand.

Regarding personal protection equipment, most of the perioperative nurses indicated that they used eye protection for their eyes; the exception was the use of high filtration surgical masks. The purpose of the surgical mask is to protect the surgical team from surgical smoke and to protect patients from droplet infection from the surgical team ${ }^{21}$. AORN has strongly recommended that perioperative personnel wear the proper personal protective equipment, such as eye protection and masks, and use an efficient smoke evacuation system ${ }^{14}$. In this study, surgical masks were reported as being used regularly but the quality of the surgical mask needs to be determined in order to ensure protection from surgical smoke or plume. The size of the particles found ranged from $0.05 \mu \mathrm{m}$ to larger than $25 \mu \mathrm{m}$ for all procedures ${ }^{26}$. Standard surgical masks filter particles $5 \mu \mathrm{m}$ or larger, and this is not adequate for protecting health professionals ${ }^{20}$, ${ }^{26}$. High filtration surgical masks need to be used because they can block smoke particles 0.1 $\mu \mathrm{m}$ in size, or smaller than 0.1 $\mu \mathrm{m}$ for viral particles ${ }^{20,27}$. AORN's recommendations include the use of high-filtration surgical masks when

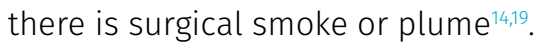
High filtration surgical masks should not be the first line of protection for surgical smoke. Institution and perioperative personnel should follow the recommended practices for electrosurgery and AORN's position statement regarding surgical smoke and bio-aerosols. Smoke should be evacuated with a smoke evacuation system and filter during surgery and personal protective equipment such as high filtration surgical masks and eyewear should be used.

Most of the perioperative nurses had not received sufficient training, demonstrations, or documentation that complied with the recommended practice regarding surgical smoke and bio-aerosols. Although most (92 per cent) knew about the hazards of surgical smoke, they did not receive additional knowledge or training regarding work-related surgical smoke. Steege et al. ${ }^{27}$ reported that 'there is a lack of training that could facilitate procedures for preventing surgical smoke.' In addition, Ball ${ }^{21}$ stated that the nurses who had more knowledge and adequate training regarding surgical smoke evacuation showed greater compliance with recommendations. Health care facilities that employ OR staff should purchase appropriate equipment and provide staff development to help implement AORN's position statement on surgical smoke and bio-aerosols ${ }^{14}$.

The new technology and equipment used to control surgical smoke also requires $O R$ staff to receive adequate training so that they can effectively operate the equipment. In addition to training, demonstrating the use and effectiveness of surgical smoke containment is also an appropriate way to ensure compliance with the recommended practices ${ }^{29}$. 
Health problems associated with surgical smoke

Most of the Thai perioperative nurses reported various health problems associated with exposure to surgical smoke. Compared to the prevalence of health problems associated with surgical smoke in Ball's study ${ }^{21}$ in the United States, the prevalence for health problems among the Thai perioperative nurses in this study was higher for each condition. A comparison of the number of respiratory problems reported by nurses in our study versus the USA included increased coughing (USA - 24.74 per cent, Thailand - 73.7 per cent), asthma (10.8 per cent, 20.9 per cent) and bronchitis (9.04 per cent, 51.9 per cent). However, Thai perioperative nurses rated the severity of these symptoms at a low level (1.78 - 3.11, Table 3$)$. The results from this study indicate that health professionals such as perioperative nurses who are exposed to surgical smoke are at risk of respiratory illness.

Several studies have supported the incidence of respiratory problems among OR nurses, as well as other health problems from exposure to surgical smoke. Plastic surgeons at Bryn Mawr Hospital in Pennsylvania reported that several OR personnel experienced upper respiratory and eye irritation, and headache and nausea during breast reduction procedures. All of the residents in the surgical specialties in Jalisco, Mexico, reported respiratory symptoms, such as sore throat (22 per cent) and the sensation of a lump in the throat (22 per cent) 5 . The surgical smoke samples were analysed and found to contain compounds of hydrogen cyanide, acetylene and butadiene, including volatile organic compounds. The perioperative nurses who were chronically exposed to surgical smoke had essentially the same risks as passive cigarette smoking victims ${ }^{30}$. In one animal study, the lung pathology of rats exposed to an operative-like smoke plume showed hypertrophy of the blood vessels, alveolar congestion and emphysematous changes. The extract of surgical smoke found chemicals including benzene, formaldehyde and acrolein, which may have been the cause of this pulmonary change. Many studies ${ }^{1,10,30}$ have confirmed that surgical smoke or plume can be the cause of eye irritation, acute or chronic respiratory infection and coughing on the part of perioperative personnel. NIOSH, OSHA, AORN, ACORN and The Joint Commission (TJC) have also recommended surgical devices such as plume evacuation systems to effectively control surgical smoke.

In this study, the nurses reported that equipment such as portable smoke evacuation units, a laparoscopic evacuation/filtration system and wall suction with inline filter were seldom or never used. This indicates that the perioperative nurses had a high likelihood of inhaling surgical smoke every day of work, leading to the development of adverse respiratory conditions. Choi et al. ${ }^{31}$ reported that the risk from chemicals such as benzene in surgical smoke needs to be controlled and recommended that operating room personnel protect themselves from the long-term health risks related to their exposure to surgical smoke.

\section{Study limitations}

This study surveyed Thai perioperative nurses regarding their adherence to recommended practice for controlling surgical smoke in operating rooms. We did not separate the study into types of surgery for clarifying which may or may not have produced a high level of surgical smoke. Future researchers should gather more information about each type of smoke evacuation system as well as which are good at handling smoke production during each surgical procedure.

\section{Conclusion}

This study clearly identified the hazards of surgical smoke with regard to the perioperative nurse's health. Programs that offer approprate teaching and training should be provided for all perioperative health personnel. This should lead to the requirement that recommended practices used for controlling surgical smoke and bio-aerosols in the operating room be implemented in an effective manner. Further research regarding surgical smoke protection should be conducted in order to examine each procedure during an operation. The recommended practices for surgical smoke and bio-aerosols prevention need to be implemented in order to reduce health risks.

\section{Recommendations}

These findings confirm the importance of compliance with the recommended practices for controlling surgical smoke and bio-aerosols. In addition, this study highlights the need for training in order to ensure the effective use of equipment and continuing education for OR personnel. Individuals in hospital organisational leadership positions should initiate programs aimed at building proficiency in the use of equipment such as portable smoke evacuation units, laparoscopic evacuation/filtration systems and wall suction with inline filters. This will minimise exposure to surgical smoke and reduce unnecessary health risks. Furthermore, each operating room needs to be monitored in order to achieve the highest standards of environmental cleanliness for health personnel and patients. Compliance with smoke evacuation devices is required in 
order to retain a healthy environment for perioperative personnel.

Future studies could compare the particles of surgical smoke before and after surgical smoke evacuation or the factors related to adherence with the recommended practice for controlling surgical smoke and bioaerosols among perioperative nurses in Thailand.

\section{Acknowledgements/ Disclosures}

The authors would like to acknowledge and thank Practice Associate Professor Dr Wendy Grube, School of Nursing, University of Pennsylvania, for an internal review of the final draft of the manuscript.

The study was partially supported by Covidien/Medtronic Pty Ltd. The authors declare no other financial conflicts of interest in this study.

\section{References}

1. National Institute of Safety and Health (NIOSH). Control of smoke from laser/ electric surgical procedures. Publication number 96-128 [Internet]. Atlanta: Centers for Disease Control and Prevention; 2014 [cited 2017 August 1]. Available from: www.cdc.gov/niosh/docs/hazardcontrol/ hc11.html.

2. Association of perioperative Registered Nurses (AORN). Guideline at a glance: Surgical smoke. AORN J 2017;105 (2):250-251.

3. International Federation of Perioperative Nurses (IFPN). IFPN Guideline on risks, hazards and management of surgical plume [Internet]. IFPN; 2015 [cited 2017 August 1]. Available from: www.ifpn.world/guidelines/ Surgical_Plume_-_Risks_Hazards_and_ Management.pdf.

4. Schultz L. An analysis of surgical smoke plume components, capture, and evacuation. AORN J 2014;99(2):289-298.

5. Hill DS, O'Neill JK, Powell RJ, Oliver DW. Surgical smoke - A health hazard in the operating theatre: A study to quantify exposure and a survey of the use of smoke extractor systems in UK plastic surgery units. J Plast Reconstr Aesthet Surg 2012;65(7):911-916
6. Sanderson C. Surgical smoke. J Perioper Pract 2012;22(4):122-128.

7. Holmes S. Factors affecting surgical plume evacuation compliance. ACORN. 2016;29(4):39.

8. Smalley $P$, Cubitt J. Clear air in surgery - A new ACORN initiative. ACORN. 2015;28(3):38

9. Tan E, Russell K. Surgical Plume and its implications: A review of the risk and barriers to a safe workplace. ACORN 2017; 30(4):33-39.

10. Okoshi K, Kobayashi K, Kinoshita K, Tomizawa Y, Hasegawa S, Sakai Y. Health risks associated with exposure to surgical smoke for surgeons and operation room personnel. Surg Today 2015;45(8):957-965.

11. Rioux M, Garland A, Webster D, Reardon E. HPV positive tonsillar cancer in two laser surgeons: Case reports. J Otolaryngol Head Neck Surg 2013;42:54

12. Association of perioperative Registered Nurses (AORN). Guideline for surgical smoke safety. In: Guidelines for Perioperative Practice pp. 477-506. Denver: AORN Inc; 2017.

13. Ilce A, Yuzden GE, Yavuz van Giersbergen M. The examination of problems experienced by nurses and doctors associated with exposure to surgical smoke and the necessary precautions. J Clin Nurs 2017; 26(11/12):1555-1561.

14. Association of perioperative Registered Nurses (AORN). AORN position statement on surgical smoke and bio-aerosols. In: Perioperative Standards and Recommended Practices pp. 125-141. Denver: AORN Inc; 2013.

15. Association of perioperative Registered Nurses (AORN). Recommended practices for electrosurgery. In: Perioperative Standards and Recommended Practices pp.123-140. Denver: AORN Inc; 2014.

16. Association of periOperative Registered Nurses (AORN). Recommended practices for a safe environment of care. In: Perioperative Standards and Recommended Practices pp.229-253. Denver: AORN Inc; 2014.

17. Association of periOperative Registered Nurses (AORN). Recommended practices for laser safety in the perioperative practice setting. In: Perioperative Standards and Recommended Practices pp.141-154. Denver: AORN Inc; 2014.

18. Association of periOperative Registered Nurses (AORN). Recommended practices for minimally invasive surgery. In: Perioperative Standards and Recommended Practices pp.155-182. Denver: AORN Inc; 2014.
19. Association of perioperative Registered Nurses (AORN). Management of surgical smoke [Internet]. Denver: AORN; n.d. [cited 2017 August 1]. Available from: www.aorn.org/guidelines/clinical-resources/ tool-kits/management-of-surgical-smoketool-kit.

20. Fitzgerald JE, Malik M, Ahmed I. A singleblind controlled study of electrocautery and ultrasonic scalpel smoke plumes in laparoscopic surgery. Surg Endosc 2012;26(2):337-342.

21. Ball K. Surgical smoke evacuation guidelines: Compliance among perioperative nurses. AORN J 2010;92(2):e1-23.

22. Australian College of Operating Room Nurses Ltd. Surgical plume. In: Standards for Perioperative Nursing in Australia $14^{\text {th }}$ ed. Adelaide, South Australia: ACORN; 2016.

23. Edwards BE, Reiman RE. Comparison of current and past surgical smoke control practices. AORN J 2012;95(3):337-350.

24. United States Department of Labor Occupational Safety and Health Administration (OSHA). Laser/electrosurgy plume [Internet]. Washington: OSHA; n.d. [cited 2017 August 1]. Available from: www.osha.gov/SLTC/ laserelectrosurgeryplume/index.html.

25. Mowbray N, Ansell J, Warren N, Wall P, Torkington J. Is surgical smoke harmful to theater staff? A systematic review. Surg Endosc 2013;27(9):3100-3107.

26. In SM, Park D-Y, Sohn IK, Kim C-H, Lim $\mathrm{HL}$, Hong S-A et al. Experimental study of the potential hazards of surgical smoke from powered instruments. Br J Surg 2015;102(12):1581-1586.

27. Steege AL, Boiano JM, Sweeney MH. Secondhand smoke in the operating room? Precautionary practices lacking for surgical smoke. Am J Ind Med 2016;59(11):1020-1031.

28. Spruce L, Braswell ML. Implementing AORN recommended practices for electrosurgery. AORN J 2012;95(3):373-387.

30. Shah NR. Commentary on 'Surgical Smoke A health hazard in the operating theatre: A study to quantify exposure and a survey of the use of smoke extractor systems in UK plastic surgery units.' Ann Med Surg (Lond) 2012;25(1):23-24

31. Choi SH, Kwon TG, Chung, SK, Kim TH. Surgical smoke may be a biohazard to surgeons performing laparoscopic surgery. Surg Endosc 2014;28(8):2374-2380. 